\title{
Incidence and management of chemotherapy-induced nausea and vomiting in women with breast cancer
}

\author{
Ocorrência e manejo de náusea e vômito no tratamento \\ quimioterápico em mulheres com câncer de mama \\ Incidencia y gestión de náuseas y vómitos en tratamiento \\ quimioterapico en mujeres con cáncer de mama
}

\author{
Thais de Oliveira Gozzo ${ }^{a}$ \\ Sarah Gomes de Souzab \\ Aline Maria Bonini Moysés ${ }^{c}$ \\ Marislei Sanches Panobianco ${ }^{d}$ \\ Ana Maria de Almeidad
}

D0l: $\quad$ http://dx.doi.org/10.1590/19831447.2014.03.42068

\footnotetext{
a Nurse. Doctor and Professor, faculty member of the Maternal Infant and Public Health departments, Ribeirão Preto Nursing School, University of São Paulo. Ribeirão Preto- São Paulo, Brazil.

b Nurse. Resident of the Integrated Multiprofessional Residency Program in health, Medical School of the $A B C$ region. Santo André- São Paulo, Brazil.

c Nurse. Master's student in the Public Health Graduate Program, Ribeirão Preto Nursing School, University of São Paulo. Ribeirão Preto-São Paulo, Brazil.

${ }^{d}$ Nurse. Associate Professor of the Maternal-Infant Nursing and Public Health Department, Ribeirão Preto Nursing School, University of São Paulo. Ribeirão Preto-São Paulo, Brazil.
}

\section{ABSTRACT}

The objective of this study was to analyze the incidence of chemotherapy-induced nausea and vomiting in women with breast cancer and identify strategies used by them to control these signs and symptoms. Data for this cross-sectional study were collected through interviews during the last cycle of chemotherapy, between August 2011 and March 2012, in a university hospital in the State of São Paulo. The sample consisted of 22 women between the ages of 31 and 70 , of whom $77.3 \%$ reported nausea and $50 \%$ vomiting during treatment. Regarding symptom management, $82 \%$ of the women reported having received some information centered on the use of prescribed medication. However, $27.3 \%$ did not know what medication they had taken. We concluded that there is a lack of systematic care and institutional protocol to guide professionals in providing standardized information to women so they can better control nausea and vomiting.

Descriptors: Toxicity. Chemotherapy. Nausea. Vomiting. Nursing.

\section{RESUMO}

Objetivou-se analisar a ocorrência de náusea e vômito em mulheres com câncer de mama durante a quimioterapia, e identificar 0 manejo utilizado para o controle desses sinais e sintomas. Pesquisa transversal, cujos dados foram coletados por meio de entrevista, no último ciclo de quimioterapia, entre agosto de 2011 e março de 2012 em um hospital universitário no interior do Estado de São Paulo. A amostra foi composta por 22 mulheres, com idade entre 31 e 70 anos, e 77,3\% relataram náusea e 50\% vômito, durante 0 tratamento. Quanto ao manejo, $82 \%$ delas afirmaram ter recebido algum tipo de informação que ficou centrada no uso da medicamento prescrito, entretanto, 27,3\% não souberam responder qual medicamento usaram. Concluiu-se que há falta de sistematização da assistência e protocolo institucional que norteiem os profissionais a fornecer informações padronizadas, possibilitando o seguimento das mulheres, a fim de terem controle mais adequado da náusea e vômito.

Descritores: Toxicidade. Quimioterapia. Náusea. Vômito. Enfermagem.

\section{RESUMEN}

Este estudio objetivó analizar la incidencia de náuseas y vómitos en mujeres con cáncer de mama durante la quimioterapia, identificar el manejo utilizado para controlar estos signos y síntomas. Estudio transversal, cuyos datos fueron recolectados por medio de entrevistas en el último ciclo de quimioterapia entre agosto 2011 y marzo 2012 en un hospital universitario en el Estado de São Paulo. La muestra consistió de 22 mujeres, con edades entre 31 y 70 años, que el 77,3\% reportó náuseas y el 50\% vómitos durante el tratamiento. Cuanto al manejo, el 82\% afirmó que habían recibido al gún tipo de información centrada en el uso de la medicación prescrita, sin embargo, el 27,3\% no supo responder cuál medicación fue utilizada. Se concluye que falta de sistematización de la atención y protocolo institucional para orientar profesionales para ofrecer información estandarizada, posibilitando el seguimiento de las mujeres para tener un mejor control de náuseas y vómitos.

Descriptores: Toxicidad. Quimioterapia. Náusea. Vómitos. Enfermería. 


\section{口INTRODUCTION}

Nausea and vomiting are the most stressful and uncomfortable symptoms reported by oncology patients. Approximately half of all cancer patients will experience nausea and vomiting during some phase of the disease. Studies indicate a variation of $38 \%$ to $60 \%$ prevalence of these symptoms during chemotherapy. ${ }^{(1-2)}$

Nausea and vomiting which are not adequately controlled may lead to other complications, such as anorexia, hydroeletrolytic imbalance, dehydration, need for or prolonged hospitalization, quality of life impairment and negative effect on daily activities. ${ }^{(3)}$ Effective treatment reduces morbidity and the risk of complications, and also prevents premature termination of chemotherapy. ${ }^{(4)}$

All chemotherapy drugs have emetogenic potential of different intensities. However, such emetogenic risk does not include nausea. ${ }^{(5)}$ The potential presented by the most commonly used drugs in breast cancer treatment protocols can be classified as: high, with a risk of vomiting of 90\% (cyclophosphamide dosage over $1500 \mathrm{mg} / \mathrm{m}^{2}$ and cisplatine); moderate, with a 30\% to 90\% risk (cyclophosphamide dosage under $1500 \mathrm{mg} / \mathrm{m}^{2}$, epirubicin and doxorubicin); low, with a $1 \%$ to $30 \%$ risk (5-fluorouracil, paclitaxel, docetaxel, methotrexate, doxorubicin lipossomal, gemcitabina and trastuzumab); and minimal, with a risk of $10 \%$ or lower (vinorelbine). ${ }^{(6-7)}$

The emetogenic risk of each cytotoxic agent for inducing nausea and vomiting determines what drug or combination of antiemetic drugs must be used. However, it is more difficult to classify the emetogenic potential of combined drugs. One example is the combination of anthracyclines with cyclophosphamide, which is the basis for many breast cancer treatment protocols. Separately, both present moderate emetogenic potential; however, their joint action results in high emetogenic potential. ${ }^{(6-7)}$

Studies indicate some factors which can favor emetic events, among them female gender, age (young), weight (the higher the body mass index - BMI - the greater the risk of presenting nausea and vomiting), drug dosage, number of cycles undergone, and light alcohol consumption. We highlight the fact that young women who do not consume alcohol, even when receiving low doses of chemotherapy drugs, as well as those with a history of vomiting during pregnancy or of motion sickness, display a greater tendency for vomiting during chemotherapy. ${ }^{(3,6)}$

Chemotherapy-induced nausea and vomiting are adverse events that should be totally controlled in most cancer patients with the development of new medications. The goal must be focused more on prevention than on treatment, so as to improve quality of life, avoid complications, and make chemotherapy treatment easier.

Despite the advances made in controlling nausea and vomiting, the treatments currently available are not effective on all patients, and available resources need to be optimized, whether pharmacological or otherwise, in order to attain better control during treatment. The introduction of more effective drugs for control of nausea and vomiting has caused positive impacts on the quality of life of many patients. In addition, clinical practice protocols such as those provided by the American Society of Clinical Oncology, which are based on systematic literature reviews, provide recommendations for managing nausea and vomiting with medication. ${ }^{(6)}$

Even with the assistance of these protocols, the health professional who has direct contact with patients during chemotherapy must assess nausea and vomiting individually. Thus, the proposed interventions are to be personalized and adapted to each patient. The nursing professional is responsible for educating patients and their caregivers about chemotherapy, including how to prevent and manage possible toxicities. ${ }^{(3)}$

What is observed in clinical practice is that this lack of specific and standardized information during chemotherapy may be associated with lack of adequate control of adverse treatment events and, consequently, with worsening of symptoms. ${ }^{(8)}$ Based on this information, we investigated whether women with breast cancer presented nausea and vomiting during their chemotherapy and how they managed these adverse events. The goals of this study were to analyze the incidence of chemotherapy-induced nausea and vomiting in women with breast cancer, and to identify the strategies used to control such nausea and vomiting.

\section{METHOD}

We conducted a descriptive cross-sectional study, assessing nausea and vomiting in women with breast cancer during neoadjuvant or adjuvant chemotherapy, carried out in the Mastology Outpatient Clinic at the Hospital das Clínicas of the Ribeirão Preto Medical School, University of São Paulo (HCFMRP-USP). The Department of Gynecology and Obstetrics of HCFMRP-USP granted permission for this study, which was approved by the Ribeirão Preto-USP Nursing School Ethics Committee (Protocol n 1319/2011).

From the estimated 100 new breast cancer cases per year treated at this clinic, we recruited women with breast cancer who were in chemotherapy during the period between April 2009 and March 2010. We used a convenience sample and included 22 women who fulfilled the following 
inclusion criteria: women over 19 years old who were in their last cycle of neoadjuvant or adjuvant chemotherapy. Criteria for exclusion were: women who could not express themselves without assistance; were diagnosed with some other type of malignant tumor; had already been treated with chemotherapy for breast cancer or some other type of malignant tumor; or were pregnant or puerperal.

For data collection, we created an instrument that gathered sociodemographic data as well as information about the chemotherapy treatment plan, antiemetic medication received before each chemotherapy cycle, incidence of nausea and vomiting during treatment, and information received for managing the consequences in daily activities. This information was obtained by interviewing participants and by reviewing their medical records. The data were organized in an Excel spreadsheet and analyzed using descriptive analysis of variables. The results are presented in charts displaying relative and absolute frequencies.

\section{口 RESULTS}

During the six months of data collection, 22 women were included in the study. They were diagnosed with breast cancer, receiving their last cycle of chemotherapy, and between the ages of 31 and 70 , with an average age of 50 years and standard deviation of 15.5 years.

Regarding sociodemographic variables: $50 \%$ of the women did not have high school diplomas; $50 \%$ did not have a partner; and $40.9 \%$ were in stage IIIB of the disease. Sixteen participants reported other comorbidities, the most common being arterial hypertension (27.3\%), and the most common medication taken before cancer diagnosis was omeprazole (47.8\%).

Among the subjects, $77.3 \%$ received neoadjuvant treatment and all participants received some type of intravenous antiemetic medication before each cycle of chemotherapy. The most commonly used drugs were ondansetron and dexamethasone for $100 \%$ of participants, followed by ranitidine, for $81.8 \%$.

Regarding the incidence of nausea, $77.3 \%$ reported feeling it at least once during chemotherapy. For most of the subjects, the symptom occurred after the second cycle of chemotherapy, and seven women reported that it persisted throughout the entire treatment. When questioned on how long it took for the nausea to intensify, answers ranged from 6 to 192 hours (eight days). The time needed for nausea to improve also displayed much variation, which indicates the subjectivity of and the difficulty of controlling this symptom.

Vomiting was reported by $50 \%$ of participants, four of whom had already presented the symptom during the first
Table 1 - Distribution of women receiving chemotherapy for breast cancer, according to age, race, marital status, level of education, stage of cancer, comorbidities and medication in use. Ribeirão Preto, SP, 2012.

\section{Variables}

\section{$\%$}

Age

$31-40$

$4 \quad 18.2$

41-50

940.9

$51-60$

$5 \quad 22.7$

$61-70$

$4 \quad 18.2$

\section{Race}

$\begin{array}{lcc}\text { White } & 17 & 77.3 \\ \text { Others } & 5 & 22.7\end{array}$

\section{Marital status}

$\begin{array}{lll}\text { With partner } & 11 & 50 \\ \text { Without partner } & 11 & 50\end{array}$

Level of education

$\begin{array}{lcc}\text { Did not complete elementary School } & 11 & 50 \\ \text { Completed elementary school } & 1 & 4.5 \\ \text { Did not complete high school } & 4 & 18.2 \\ \text { Completed high school } & 3 & 13.6 \\ \text { Higher education diploma } & 3 & 13.6\end{array}$

\section{Stage of cancer}

$\begin{array}{lll}\text { IIIB } & 9 & 40.9 \\ \text { IIA } & 8 & 36.4 \\ \text { Other } & 5 & 22.7\end{array}$

\section{Comorbidities}

$\begin{array}{lll}\text { Hypertension } & 6 & 27.3 \\ \text { Dyslipidemia } & 4 & 18.2 \\ \text { Other } & 6 & 27.3 \\ \text { None } & 9 & 40.9\end{array}$

Medication used before cancer diagnosis*

\begin{tabular}{lcc} 
Omeprazole & 11 & 47.8 \\
Antihypertensives & 10 & 43.5 \\
Other & 7 & 30.4 \\
\hline
\end{tabular}

Source: Project database.

* Participant could report more than one medication.

cycle. Regarding the time elapsed before vomiting intensified, answers ranged from 24 to 120 hours (five days). This symptom improved any time between 2 and 360 hours (15 days).

Regarding symptom management, $53 \%$ of the women who presented nausea and $27.3 \%$ of those who reported 
Table 2 - Distribution of women receiving chemotherapy for breast cancer, according to chemotherapy category, protocol chemotherapy drugs and intravenous antiemetic medication. Ribeirão Preto, SP, 2012.

\section{Variables}

\section{$\mathbf{N}$}

$\%$

\section{Chemotherapy category}

Neoadjuvant

$17 \quad 77.3$

Adjuvant

$5 \quad 22.7$

\section{Chemotherapy Protocol}

Neoadjuvant

$\begin{array}{ccc}\text { EC-T } & 7 & 31.8 \\ \text { EC-TH } & 7 & 31.8 \\ \text { FEC } & 3 & 13.6 \\ \text { Ajuvant } & & \\ \text { EC-T } & 2 & 9.1 \\ \text { FEC } & 3 & 13.63\end{array}$

\section{Intravenous antiemetic medication*}

\begin{tabular}{lcc} 
Ondansetron & 22 & 100 \\
Dexamethasone & 22 & 100 \\
Ranitidine & 18 & 81.8 \\
Omeprazole & 2 & 9.1 \\
Palonosetron & 9 & 40.9 \\
Bromopride & 1 & 4.5 \\
\hline
\end{tabular}

Source: Project database

*Participant may have received more than one medication per cycle.

vomiting used only drug remedies. We highlight that $94.4 \%$ of women who presented nausea and $77.7 \%$ of those who presented vomiting reported having been given an orientation about taking a prescribed medicine (Table 3).

The women also reported changes in their daily lives related to the incidence of nausea and vomiting, such as not being able to carry out their usual activities and not participating in social activities due to their symptoms (Table 3).

In addition to these changes, $27.2 \%$ and $13.6 \%$, respectively, reported loss of appetite due to nausea and vomiting; and $63.6 \%$ and $31.8 \%$, respectively, reported other changes in eating habits due to these symptoms, such as not eating raw foods and avoiding fried foods, sweets and red meat, because they caused aversion.

Four participants reported not having received orientation regarding chemotherapy before it was initiated and $81.8 \%$ reported having received such information. However, we highlight the fact that, although the orientation given by professionals centered on drug management, when questioned about which drugs they had taken at home in order to manage nausea and vomiting, $27.3 \%$ of participants could not provide an answer.

All of the interviewees reported having experienced other adverse effects besides nausea and vomiting. The most commonly cited were skin rashes (41\%), mucositis (41\%), dry mouth (31.8\%), fatigue (31.8\%) and alopecia (22.7\%). Together with the participants, we identified which adverse effects they considered to be most stressful. Nausea was considered the most stressful for $22.7 \%$, followed by alopecia for $18.2 \%$, diarrhea for $18.2 \%$, changes in taste for $18.2 \%$ and vomiting for $13.63 \%$.

\section{口DISCUSSION}

The results of this study indicate that the women took antiemetic drugs recommended by international protocols, such as 5-hydroxytryptamine-3 antagonists (ondansetron, palonosetron), which are considered the gold standard for acute nausea and vomiting after chemotherapy. However, the general management of these events is still a problem for women with breast cancer..$^{(9)}$

When antiemetic drugs are used appropriately, episodes of nausea and vomiting can be reduced considerably. ${ }^{(10)}$ In the present study, all participants received intravenous antiemetics. However, we determined that throughout the entire chemotherapy treatment, $77.3 \%$ of the women presented nausea and 50\% presented vomiting, regardless of what chemotherapy protocol was used.

The data suggest that despite the use of antiemetics, there is a gap in the health team's individual evaluation of the women's symptoms and their evolution. In this sense, we observed that the drugs prescribed were all the same, with their dosage adjusted to the patient's condition and to the dosage of the chemotherapy, regardless of the symptoms presented and their frequency and intensity. Information needs to be continually circulating, in that the nursing team that cares for patients throughout each cycle of chemotherapy should collect information on the symptoms presented. They should also reinforce orientation, including the necessary precautions for avoiding additional health complications, ${ }^{(11)}$ and appropriately managing those that have already occurred.

In an observational study of 143 women with breast cancer, $70 \%$ of patients presented delayed nausea, similar to this study. This type of nausea is difficult to control, regardless of which antiemetics are available and taken by patients. We emphasize the importance of using antiemetics appropriately for reducing the incidence of severe chemotherapy-induced nausea and vomiting. ${ }^{(12)}$ 
Table 3 - Distribution of women receiving chemotherapy for breast cancer according to use of oral antiemetic, symptom incidence, symptom management, orientations received and types of orientation. Ribeirão Preto, SP, 2012.

\begin{tabular}{|c|c|c|c|c|}
\hline \multirow{2}{*}{ Variable } & \multicolumn{2}{|c|}{ Nausea } & \multicolumn{2}{|c|}{ Vomiting } \\
\hline & $\mathbf{N}$ & $\%$ & $\mathbf{N}$ & $\%$ \\
\hline \multicolumn{5}{|l|}{ Incidence of symptom } \\
\hline Yes & 17 & 77.3 & 11 & 50 \\
\hline No & 5 & 22.7 & 11 & 50 \\
\hline \multicolumn{5}{|l|}{ Therapy used } \\
\hline Drug & 9 & 53 & 3 & 27.3 \\
\hline Non-drug & $7^{*}$ & 41.1 & $7^{* *}$ & 63.6 \\
\hline Persistent symptoms & - & - & 1 & 9.1 \\
\hline \multicolumn{5}{|l|}{ Management orientation } \\
\hline Yes & 18 & 82 & 18 & 82 \\
\hline No & 4 & 18 & 4 & 18 \\
\hline \multicolumn{5}{|l|}{ Type of orientation } \\
\hline Take prescribed medication & 17 & 94.4 & 14 & 77.7 \\
\hline Change eating habits*** & 1 & 5.6 & 1 & 5.6 \\
\hline Does not remember & - & - & 1 & 5.6 \\
\hline Go to a health care unit & - & - & 2 & 11.1 \\
\hline \multicolumn{5}{|l|}{ Changes in daily activities } \\
\hline \multicolumn{5}{|l|}{ Interferes with daily activities } \\
\hline Yes & 8 & 36.3 & 4 & 18.2 \\
\hline No & 14 & 63.6 & 18 & 81.8 \\
\hline \multicolumn{5}{|l|}{ Interferes with social activities } \\
\hline Yes & 7 & 31.8 & 4 & 18.2 \\
\hline No & 17 & 77.2 & 18 & 81.8 \\
\hline
\end{tabular}

Source: Project database.

*Ingesting liquids, such as juice and water

** Four reported that they did nothing and three ingested liquids such as juice and tea.

*** Eating every three hours for nausea and ingesting light foods for vomiting.

We also highlight the lack of knowledge displayed by participants regarding what antiemetic medication they take at home. Lack of knowledge of patients and caretakers can lead to other unpleasant effects and interfere with the safety and guaranteed effectiveness of medications, due to their improper use..$^{(13)}$

Although most participants (82\%) reported having received orientation about chemotherapy and its adverse effects, we observed that only drug remedies were indicated to manage nausea and vomiting. We also found a gap in their knowledge about antiemetic medication, which may be related to the quality of information and/ or how the professional transmits it, as well as the par- ticipant's level of education. It is agreed that information on medication must touch on its purpose, characteristics, actions and reactions, in order to improve the quality of the patient's treatment. ${ }^{(11)}$

Health professionals must be vigilant in order to evaluate and offer support to patients who present nausea and vomiting. A qualitative study which investigated the experiences of European and American patients with nausea observed that participants received little orientation from health professionals, and what they did receive was centered on drug management. The authors concluded that health professionals must educate patients about all available management strategies for nausea-related symptoms..$^{(14)}$ 
It is essential that nurses monitor the severity of adverse events individually and adapt antiemetic medication accordingly to minimize such events, always based on protocols of good clinical practice. The use of valid and standardized instruments such as procedures which systematize the evaluation of nausea and vomiting also helps standardize records and management of these adverse events. ${ }^{(15)}$

Dietary measures must be combined with pharmacological management of nausea and vomiting, adjusted to each patient's needs, respecting their preferences and eating habits. ${ }^{(16)}$ Simple measures that can favor the management of these symptoms include spreading out meals over the day, avoiding fatty and highly seasoned foods, not lying down after meals, giving preference to cold or room temperature food, and avoiding liquids during meals (although a daily water intake of 8 to 12 cups is recommended). ${ }^{(16-17)}$

Non-pharmacological measures are also available, such as the use of phytotherapeutics, especially ginger, whose effectiveness for controlling nausea and vomiting has been demonstrated in various situations. Acupuncture, acupressure, hypnosis, relaxation, aromatherapy and yoga have also been used, and clinical studies have presented significant results regarding their use.(18) However, these procedures require specific training, as well as a suitable place for their implementation, which is not the reality of many Brazilian services that treat patients through the Unified Health System.

Table 4 - Distribution of women receiving chemotherapy for breast cancer according to their knowledge of oral antiemetics and other medications being taken. Ribeirão Preto, 2012.

\section{Variable}

\section{Patient's knowledge of medication}

$\begin{array}{lcc}\text { Was able to answer } & 13 & 59.1 \\ \text { Was not able to answer } & 6 & 27.3 \\ \text { Did not take any } & 3 & 13.6\end{array}$

\section{Medications *}

$\begin{array}{ll}\text { Ondansetron } & 8 \\ \text { Metoclopramide } & 6 \\ \text { Bromopride } & 6 \\ \text { Omeprazole } & 4 \\ \text { Dimenhydrinate } & 1 \\ \text { Ranitidine } & 1\end{array}$

Source: Project database.

*Participant may have received more than one medication per cycle.
Notwithstanding the availability of these measures in the system, or whether patients seek them spontaneously, or their combination with pharmacological measures, we reinforce the importance of educating and orienting patients and caretakers so they can successfully manage nausea and vomiting, regardless of what measure is chosen.

Protocols containing systematized orientations regarding drug management and other measures, as well as professional training, are clearly necessary. Management protocols are a set of recommendations developed systematically and based on current scientific knowledge, which help manage a specific health problem and orient the workflow, conduct and clinical procedures of health care professionals. We emphasize that the use of protocols is not without limitations, for the actions described may be restricted to preestablished procedures and may not meet the clinical demands of several different situations. ${ }^{(19)}$

In a study which assessed the challenges and application of international protocols for controlling nausea and vomiting in several European countries, from the viewpoint of nurses who work in oncology units and centers, the author states that nurses must be encouraged to work collaboratively with their peers to develop local protocols for managing these adverse events. Such protocols, different from those developed by doctors and pharmacists, must approach the patient holistically, managing nausea and vomiting with pharmacological, non-pharmacological and, above all, educational measures. ${ }^{(18)}$

When developing protocols, we must consider the perspective of patients undergoing outpatient chemotherapy in terms of their quality of life. Based on this perspective, it is possible to develop guidelines for nursing care to adequately control and manage the adverse events of chemotherapy. ${ }^{(20)}$

\section{CONCLUSIONS}

Although $82 \%$ of participants reported having received orientation regarding management of nausea and vomiting, the information they received was limited to the use of medication and was not effective. This shows the need for continuing professional education based on good clinical practices, and for elaborating and effectively implementing protocols to standardize orientations about nursing care for women with breast cancer, aimed at evaluating and managing adverse events.

We also observed a lack of assessment and follow-up of the participants regarding adequate management of nausea and vomiting via prescribed medication and the orientation received. These data confirm the need for further 
studies that will accompany these women, cycle by cycle, to evaluate the incidence of gastrointestinal toxicities.

The major limitation of these studies is the small number of participants, a fact which did not allow for an association test among variables. In spite of this limitation, the results suggest that nurses who work with oncology patients must use educational methods to transmit information on treatment, including the management of any adverse events, thus favoring proper self-care, reduction of anxiety, and improvement in quality of life.

\section{口REERENCES}

1. Piccart MJ, Leo A, Beauduin M, Vindevoghel A, Michel J, Focan C, et al. Phase II trial comparing two dose levels os epirubicin combined with cyclophosphamide, cyclophosphamide, methotrexate, and fluoracil in node-positive breast cancer. J Clin Oncol. 2001;19(12):3103-10.

2. Linden HM, Haskell CM, Green SJ, Osborne CK, Sledge GW Jr, Shapiro CL, et al. Sequenced compared with simultaneous anthracycline and cyclophosphamide in high-risk stage I and II breast cancer: final analysis from INT-0137. J Clin Oncol. 2007;25(6):656-61.

3. Santos M, Pinho M, Silva S, Dias V. Estudo sobre emese aguda e tardia em doentes a efectuar quimioterapia, alta e moderadamente emetizante, em internamento. Onco News. 2008;5:4-8.

4. Huertas-Fernándes MJ, Martínez-Bautista MJ, Sánchez-Martínez I, Zarzuela-Ramirez M, Baena-Cañada JM. Análisis de la efectividad de un protocolo de antiemesis implantado en la unidad de oncologla. Farm Hosp. 2010;34(3):125-38.

5. Olver I, Molassiotis A, Aapro M, Herrstedt J, Grunberg S, Morrow G. Antiemetic research: future directions. Support Care Cancer. 2011;19 Suppl 1:S49-55.

6. Roila F, Herrstedt J, Aapro M, Gralla RJ, Einhon LH, Ballatori E, et al. Guideline update for MASCC and ESMO in the prevention of chemotherapy- and radiotherapy-induced nausea and vomiting: results of the Perugia consensus conference. Ann Oncol. 2010;21 Suppl 5:232-43.

7. Molassiotis A, Saunders MP, Valle J, Lorigan P, Wardley A, Levine E, et al. A prospective observational study of chemotherapy-related nausea and vomiting in routine practice in a UK cancer center. Support Care Cancer. 2008;16(2):201-8.

\section{Author's address:}

Thais de Oliveira Gozzo

Escola de Enfermagem de Ribeirão Preto-USP

Av. Bandeirantes, 3900, Monte Alegre

14040-902, Ribeirão Preto, SP

E-mail: thaisog@eerp.usp.br
8. Almeida EM, Gutierrez MGR, Adami NP. Monitoramento e avaliação dos efeitos colaterais da quimioterapia em pacientes com câncer de cólon. Rev Latino-Am Enfermagem. 2004;12(5):760-6.

9. Basch E, Prestrud AA, Hesketh PJ, Kris MG, Feyer PC, Somerfield MR, et al. Antiemetics: American Society of Clinical Oncology clinical practice guideline update. J Clin Oncol. 2011; 29(31):4189-98.

10. Jakobsen JN, Herrstedt J. Prevention of chemotherapy-induced nausea and vomiting in elderly cancer patients. Crit Rev Oncol Hematol. 2009;71(3):214-21.

11. Telles Filho PCP. Conhecimento e adesão à terapêutica medicamentosa após a alta hospitalar. RECENF: Rev Técnico-Cientifica Enferm. 2007;5(17):64-9.

12. Booth CM, Clemons M, Dranitsaris G, Joy A, Young S, Callaghan W, et al. Chemotherapy-induce nausea and vomiting in breast cancer patients a prospective observational study. J Support Oncol. 2007;5(8):374-80.

13. Marodin G, Maldaner OA. Relação educativa entre farmacêutico e usuário em postos de distribuição de medicamentos da rede pública. Rev Gaúcha Enferm. 2006;27(4):610-7.

14. Molassiotis A, Stricker CT, Eaby B, Velders L, Coventry PA. Understanding the concept of chemotherapy-related nausea: the patient experience. Eur J Cancer Care. 2008;17(5):444-53.

15. Caponero R. Consenso brasileiro de náuseas e vômitos em cuidados paliativos. Rev Bras Cuidados Paliativos. 2011;3(3)Supl 2. Disponível em: http://www. cuidadospaliativos.com.br/img/din/file/SuplementoCP_Nausea_Vomito_ Final_D.pdf.

16. Benarroz MO, Failace GBD, Barbosa LA. Bioética e nutrição em cuidados paliativos em adultos. Cad Saúde Pública. 2009;25(9):1875-82.

17. Cancer Care Ontario. Action Cancer Ontario. Symptom management pocket guides: nausea \& vomiting [citado 2013 maio 10]. 2010. Disponível em: https://www.cancercare.on.ca/CCO_DrugFormulary/Pages/FileContent. aspx?fileld $=97473$.

18. Vidall C. Chemotherapy induced nausea and vomiting: a European perspective. Br J Nurs. 2011;20(10):22-8.

19. Werneck MAF, Faria, HP, Campos, KF. Protocolo de cuidados à saúde e de organização do serviço. Belo Horizonte: Nescon/UFMG; 2009. Disponível em: https:// www.nescon.medicina.ufmg.br/biblioteca/imagem/1750.pdf

20. Chaves PL, Gorini MIPC. Qualidade de vida do paciente com câncer colorretal em quimioterapia ambulatorial. Rev Gaúcha Enferm. 2011;32(4):767-73.
Received: 26.08.2013

Approved: 09.05.2014 